\title{
Molecular Era of the Forensic Science
}

\section{Yorran Hardman A. Montenegro', Stephanie Evelyn França Guimarães ${ }^{1}$, Estefany Gabriela Luiz de Araújo ${ }^{1}$, Rosália Santos Ferreira $^{1}$, Ellen Rachel de Almeida Martins ${ }^{1}$, Maria Karoline da Silva Marcelino ${ }^{1}$, Denise de Queiroga Nascimento ${ }^{2}$ and Geilza Carla de Lima Silva ${ }^{2}$}

${ }^{1}$ Laboratório de Genética e Biologia Molecular (LGBM). Universidade Estadual da Paraíba (UEPB). Campus I. Rua Baraúnas, 351. Bairro Universitário. Campina Grande-PB, Brazil (CEP 58429-500).

${ }^{2}$ Laboratório de Imunopatologia Keizo Asami (LIKA). Universidade Federal de Pernambuco (UFPE). Av. Prof. Moraes Rego, S/№. Cidade Universitária. Recife-PE, Brazil (CEP 52171-011).

\begin{abstract}
Forensic science is an interdisciplinary area that is intimately related between the fields of physics, biology, chemistry, mathematics and forensic opportunity sciences, with the aim of supporting criminal investigations and civil justice. Forensic Entomology enters as the most promising and attention-grabbing course, especially for its versatility in identifying morphological characteristics in species identification, requiring new analytical tools such as microcopy and molecular analysis. With regard to the Molecular Age in Forensic Science, new technologies can be applied in the research field regarding necrobiota, a new and promising molecular tool that indicates the possible places of displacement of the body and people involved; phenotyping as an analytical tool for the phenotypic identification of the possible appearance of the suspect or missing person; epigenetics in the identification of suspects in the case of homozygous twins. All new tools open up the numerous possibilities for further development of Forensic Science, allowing greater agility in resolving criminal investigations.
\end{abstract}

Keywords: Phenotyping; Necrobiota; Epigenetics; COI-I.
Received

June 19, 2018

Accepted

August 10, 2018

Released

August 31, 2018

Full Text Article

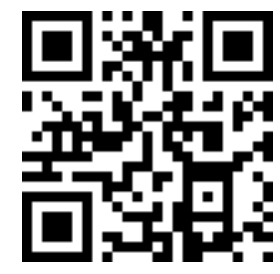

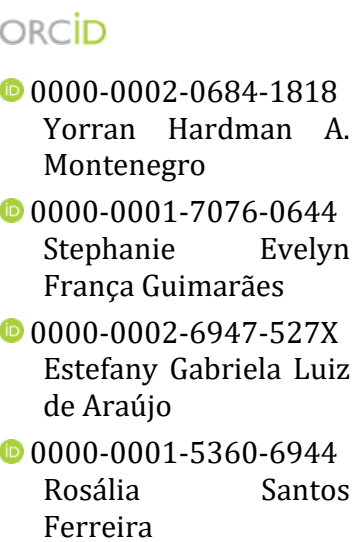




\section{Introduction}

Forensic science is an interdisciplinary area that establishes intrinsic relationships between the fields of physics, biology, chemistry, mathematics and forensic opportunity sciences, with the aim of supporting criminal investigations and civil justice. For this, it provides the principles and techniques that facilitate the investigation of the crime, assisting in identification, recovery, reconstruction and analysis of the evidence during a criminal investigation (Sharma et al., 2013).

Among the many areas of forensic activity, we can make mention of the papiloscopy, which analyzes fingerprints, and ballistics, an integral discipline of criminalistics that studies firearms, their slingshot and the effects of this shots produce. Others question like who have been involved in criminal offenses, seeking clarification and proof of their occurrence will answer with this investigations (Mądra et al., 2015).

As for the biological area, genetics has advanced substantially in recent years. Only a small sample of blood, saliva, skin or semen may be sufficient to identify a victim or suspect. Moreover, in the last two decades another sub-area of Biological Science has attracted interest from experts and people linked to judicial institutions: the forensic entomology. According to Mądra et al. (2015), this is an area that studies arthropods that can properly aid in the

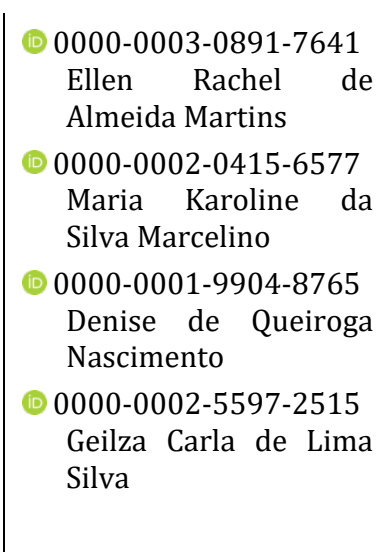

outcome of a crime. Such invertebrates, according to Sharma et al. (2013), can characterize the site, the time the event occurred and possible ways of how it happened.

With the assistance of genetics, new areas of research such as the use like the epigenetics, especially with the objective of tracing the recognition of individuals, and reducing the number of suspects. The term epigenetic has been modified over the time through various scientific researches and is defined as a heritable change in gene expression, with no change in the nucleotide bases of DNA. According to Kader and Ghai (2015) this includes modifications in the activity of histone proteins, DNA methylation, chromatin remodeling by RNAs and, last but not least, non-coding of some gene products, influenced by senescence and the lifestyle of that individual reflecting like a strong evidence of possible age, sex and phenotype of suspects in forensic cases using molecular markers.

Analyzing the methylated DNA, the observed shows a benefit in the high specificity besides a minimum consumption of material collected and little susceptibility to degeneration by external and environmental factors (Kader and Ghai, 2015). Several studies have demonstrated this specificity for blood, semen, saliva, epidermal tissues, as well as the epigenetic distinction of identical, previously impossible to differentiate twins. Other applicability is the study of the predicted age and the 
chronological age of the suspect by semen and saliva samples, estimated by the chemical alterations that DNA undergoes during the life (Lee et al., 2015, Matos, 2016).

In addition to epigenetic use as a crime elucidation tool, another area has attracted attention in recent years: DNA forensic phenotyping (DFP) (Virmond et al., 2016). The DFP is a method that predicts the physical characteristics of an individual from the biological material found at the investigated local. The success of this methodology is based on single nucleotide polymorphisms (SNP), used in forensic analysis because they have special characteristics, like a predictive capacity of biogeographic origin and to carry the phenotypic information. This biogeographic precision facilitates the understanding of the phenotypic relationships with the environment and the phenotypic characteristics that reference the typical of the population in question (Fagertun et al., 2015, Virmond et al., 2016).

Even with all the technological advancement of the implementation of this new technology - especially in the field of forensic investigation -, it's necessary to keep in mind that this phenotypic prediction has some crucial difficult. These difficult relate e.g. to the trio: genotype-phenotype-environment. Phenotypic characteristics may be simple when expressed by genes, or complex, when altered by environmental factors. This combination of factors express directly influences the final phenotype of the individual, especially the face. Such environmental factors are relevant and important for what will analyze. Many studies have focused on SNPs related to human pigmentation since it is a profile of high heredity and sufficient to provide phenotypic data of interest to individuals.

Last but not least, the classic area of forensic investigation has undergone gradual advances for precise determination and species-specific identification: the Forensic Entomology.
Among the most common insects in forensic investigations are those of the order Diptera, which are classified into two suborders: Nematocera and Brachycera. These are associated with the stages of development of a decomposing body. From the deposition of their eggs, as a natural tendency, to stages of their development, it's possible to determine the date of death of the individual and, if possible, the occurrence circumstances of the event (Sharma et al., 2013).

Focus into this scientific universe, it was decided to objectify the mensuration of the main advances of Forensic Science in recent years. These advances will be restricted to the areas of Forensic Entomology, Forensic Genetics and Forensic Microbiology.

\section{Methodology}

The systematic literature review is a form of research that uses literature as sources of data on a particular subject. The purpose of this paper is to integrate information that can be approached in studies carried out separately, later to present conflicting and/or coincident results in order to assist in future research (Sampaio and Mancini, 2007).

The databases used in this systematic review were Science Direct, NCBI and Scientific Eletronic Library Online (SCIELO), being this choice justified by the large number of journals found in them, in the areas of entomology, systematic, techniques in molecular biology applied to forensic investigation.

For the search of the articles, some combinations of keywords were used "Entomology Forensic", "Decomposing Bodies", "Human Cadaver Insects", "Keys Identification Insects", "Forensic Genetics", "Investigation with the genetic forensic", "Forensic Epigenetics", "Methylation of DNA", "CpG Islands", "Forensic Genetics", "Molecular markers", "Epigenetic analysis". The research was occurred during the period 
from February 1 to 15, 2018, objectifying to understand the advances of forensic entomology, forensic genetics and forensic microbiology as a criminal science. In this context, it was decided to select works in the English, Portuguese and French languages, with an experimental design and satisfactory results, published between 2013 to actual days, thus ensuring an updated bibliographic survey. It was used as criteria of exclusion articles that did not portray the theme as well as those that were not published between 2013 and 2018.

\section{Results and discusson}

Forensic Entomology
Among the numerous
specializations of the forensic

entomology, taxonomic and systematic identification is essential for any procedure. Since your creation, the identification of necrophagous insects requires specific entomological knowledge, in addition to appropriate physical space; it's recommended for Criminals to associate with entomologists, collecting entomological evidence, store and sending for the purpose of correct identification. To aid in this practice, some tools can be used, one of them is the microscopy devices.

Scanning electron microscopy it's a flash tool and accurate in the identification and can be used to aid different species of forensic interest, especially new morphological characteristics using in the speciespecific identification, such as Diptera.
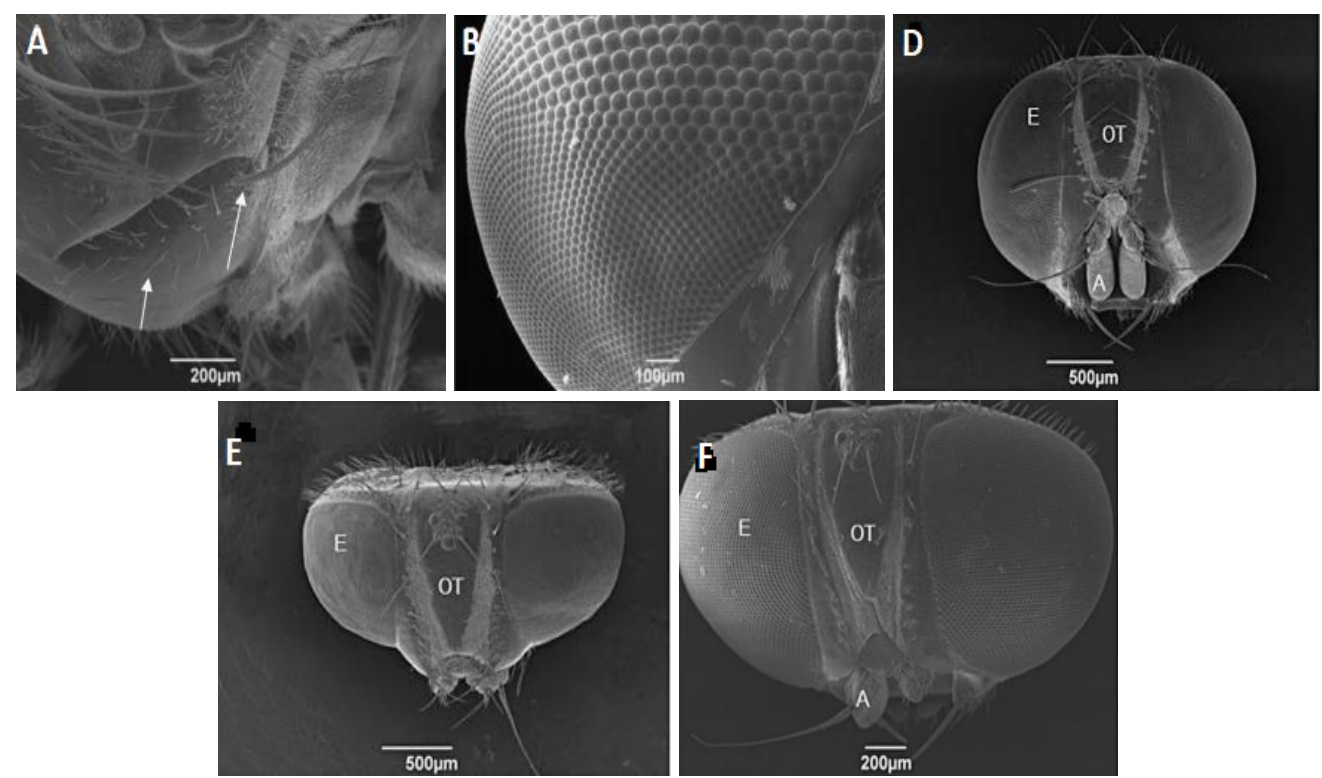

Figure 1. Scanning electron micrograph. (A) Katepisternal arrow of female B. bipuncta adult in lateral view with posterior bristle; (B) View of the composite eye ommatidia the adult male of $B$. bipuncta. (D) Pair of large compound eyes (E), ocular triangle (OT) and antenna (A) of female Ophyra aenescens. (E) Pair of large compound eyes (E), ocular triangle (OT) of female Ophyra albuquerquei. (F) Pair of large eyes (E), ocular triangle (OT) and antennas (A) of the Ophyra chalcogaster species. Fonte: Carriço et al. (2014). 
Colonizing species are attracted by the gases released by the decomposition of the body and the microbial community just minutes after death. This behavior makes them indispensable for theatanological use in the investigation forensic, precisely because of the essential functions of each taxonomic character. Microscopy appears as a special tool for such analyzes (Carriço et al., 2014).

Carriço et al. (2014) selected six species of Diptera from the Muscidae Family and described the katepisternals in the females of Morellia humeralis and Biopyrellia bipuncta; ommatidia of the eyes composed of $B$. bipuncta male; the female antennae of Ophyra aenescens and Ophyra albuquerquei and the ocular triangle of the last two species and $O$. chalcogaster examined by scanning electron microscopy to help increase the anatomical database in flies for the forensic importance.

Samerjai et al. (2016) also opted for scanning electron microscopy to observe the morphology of the immature stages of two species of meat flies Boettcherisca nathani and Lioproctia pattoni (Diptera: Sarcophagidae) (Figure 2 ). They analyzed that the third instar of the two species deferred markedly on the spines between the prothorax and the mesothorax. B. nathani has thinner triangular spines, with those of the posterior region thinner than the anterior region; while L. pattoni has robust triangular spines with one or two anterior tips, with smaller triangular and conical shape, grouped two to four laterally at the posterior extremity.

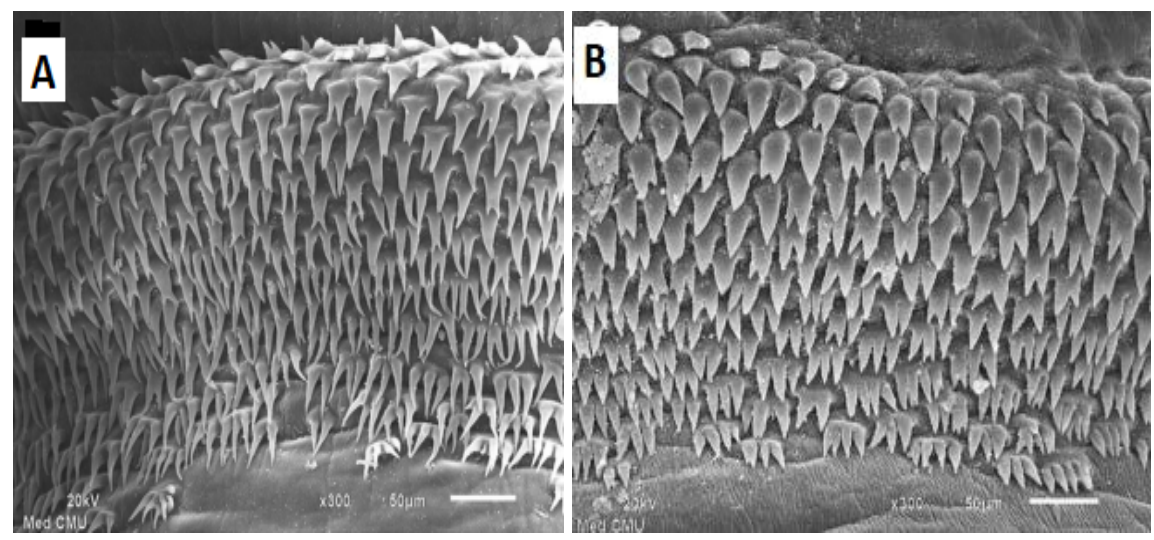

Figure 2. Scanning electron microscopy. (A) Third larval instar of B. Nathani showing spines located at the anterior margin of the mesothorax showing a triangular shape more or less thin anteriorly, while slender later. (B) Third instar L. pattoni showing thorns on the anterior margin of the mesothorax demonstrating a robust triangular shape with one or two anterior tips, while smaller and conical triangular shape, laterally grouped from two to four posteriorly. (Fonte: Samerjai et al. 2016).

The use of these techniques opt for the optimization of the identification process of the species in the forensic context, being able to characterize morphological individualities in greater detail with a field of view allowing the more specific characterization of the observing.
Recent techniques involving Forensic Entomology have conquered many professionals from the most diverse areas of biological knowledge, resulting in a concrete collection of entomological evidence from the criminal area. Nevertheless, new techniques have been developed to 
specify more precisely the Postmortem Interval. One of them is the molecular applicability in Entomological analysis.

\section{Forensic Entomology and Molecular Tools}

Molecular markers for forensic practice have been an alternative for more specific studies on species-specific identification with genetic variability. Problems involving the creation of entomofauna in the laboratory as well as the complexity of species recognition by morphological characters, open the way for the molecular identification appears as a reliable tool. They are effective methods for identifying individuals at any stage of life, including immature stages and in any preservation condition (Alves et al., 2014).

\section{Cytochrome C oxidase subunit}

I. Studies dating from 1997 elucidated to identify more precisely a specific region for this type of study in eukaryotes, called DNA BARCODE, located in the Cytochrome C Oxidase Subunit I (COI-I). The main feature of this localization is the ability to retrieve gene sequences from samples in advanced states of decomposition or inadequate state of preservation (Hebert and Gregory, 2005).

In Europe, for example, the decomposition of human bodies attracts approximately 30 species of the Faniidea family, especially in forest environments or habitats near the tropics (Mądra et al., 2015). The main difficulty found in this family in medico-legal investigations is the identification of females with regard to their morphological characteristics (Szpila et al., 2015).

To solution of this problem, Grzymarck et al. (2017) investigated three lines for species-specific identification of the Faniidea family. These were: (i) intra- and interspecific investigations of gene diversity to identify barcoding gap with the help of databases; (ii) identification of species through the COI-I mini-regions; (iii) obtaining sequences that exhibit monophyletic characteristics in phylogenetic analyzes. 27 species were identified, including 13 unpublished in COI-I sequencing. Their main finding was that the databases did not provide information of species of forensic interest, in contrast, their unpublished data helped in the expansion of information for the European entomological identification.

Some problems associated with the COI-I technique (DNA present in mitochondria) have been identified by some authors. These, concern both the vulnerability of the application of mitochondrial DNA (mtDNA) research techniques, as well as the possibility of intraspecific variations of the target region, that is, in these interspecific regions there is high similarity of COI-I sequence (Pentinsaari et al., 2014).

To resolve possible problems, it's necessary to introduce other markers in the DNA for investigation. Among the new candidates are: Cytochrome C Oxidase Subunit II (COI-II), Cytochrome b (cyt b), Ribosomal internal transcribed spacer 2 (ITS2) and Elogation factor 1 alpha (ef1 $\alpha$ ) genes (Tsang et al., 2014).

Zajac et al. (2016) used the marker ef1 $\alpha$ to complement the information obtained by the COI-I sequence analysis. The family of interest for forensic investigations, used by the researchers was the Piophilidae (Diptera), especially to their presence in corpses with 3-4 days (forensic importance) as well as their presence in high altitude areas. The great differential of this research was the collection of species in 10 different locations in Europe: Spain (3 locations), Germany (3 locations), Portugal (2 locations), Poland (1 location) and Switzerland (1 location) thus identifying nine species of forensic interest, with a minimum ambiguity of results between COI-I and ef1 $\alpha$ techniques ranging from $1-7 \%$ only. According to the researchers, the interspecific difference that hinders the analysis of COI-I was null on the analyzes 
of the nuclear marker ef1 $\alpha$. Finally, it's suggested that the identification of families using the nuclear marker is more accurate than the COI-I mitochondrial marker, however, the latter is better in the species-specific identification, concluding that a complementary analysis between marker nuclear and mitochondrial would be a viable alternative for the precise identification.

Tuccia et al. (2016) identified the main primers used in the investigation of the COI-I region (Figure 3) for Drosophila yakuba. In a letter to the editor of Forensic Science International: Gene, they also elucidated the major challenges in identifying Calliphoridae species with regard to the large number of primers for their identification, as well as performing a review on forensic entomology in the last years.

It has been observed that the use of molecular investigations in the identification of species through BARCODE DNA analyzes, as well as corresponding phylogenetic analyzes. The precision of the molecular method becomes more practicable than the creation of these organisms in the laboratory, making the entomological studies with molecular tools more effective to the forensic investigator. The tool has evolved greatly in recent years and has become essential in an era of expansion of Molecular Biology.

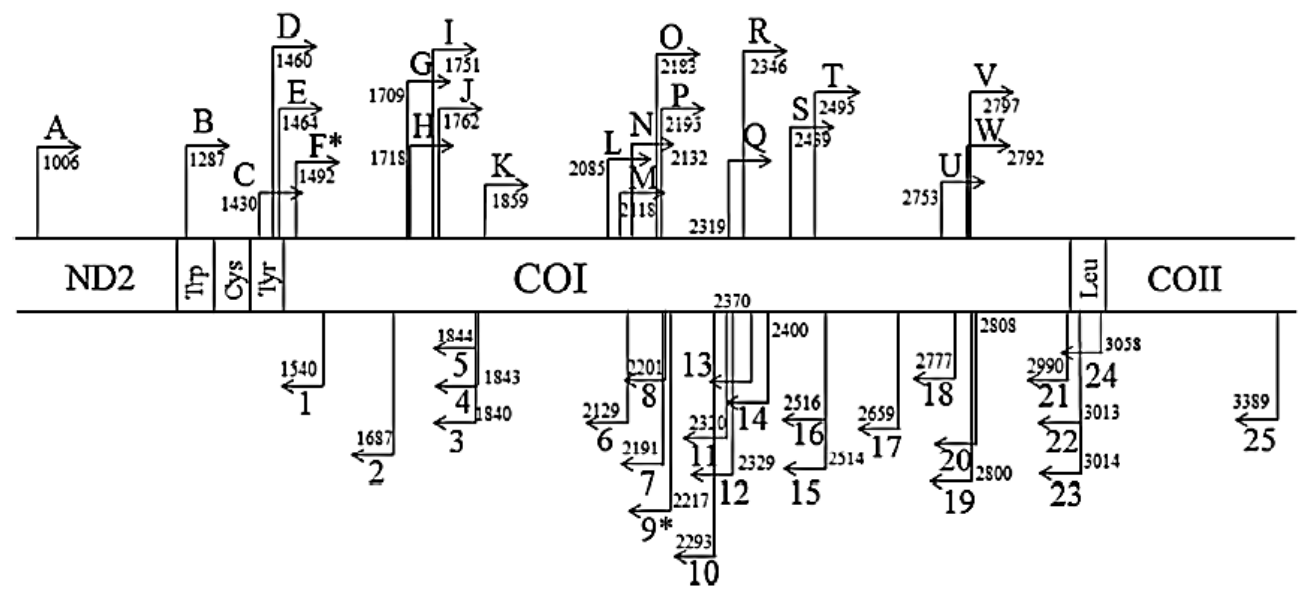

Figure 3. Gene COI and main primers used. Gene COI with its forward primers marked with alphabetic letters and its reverse primers are labeled with numbers. The position number refers to the Drosophila yokuba sequence. Fonte: Tuccia et al. (2016).

Recent techniques involving Forensic Entomology have conquered many professionals from the most diverse areas of biological knowledge, resulting in a concrete collection of entomological evidence from the criminal areas. Nevertheless, new techniques have been developed to specify more precisely the Postmortem Interval. One of the most recent bets for this estimate has been the investigation of the interaction between bacterial community and its influence on the Precolonization Interval Community of corpses (Edmund et al., 2014).

\section{Forensic Microbiology}

This technique is called PreAppearance Interval (PAI). This tool estimates the time of bacterial colonization and the beginning of the colonization of the insects. This new technique is being regulated by the Entomological Society of America 
(Bellelli and Campobasso, 2017) and surfer new adjusts.

The influence of the microenvironment of the body's local on cadaveric decomposition is one of the forms of involvement in the interaction of necrobial communities (biome of microorganisms in the decomposed body) and epinecrotic microbiome (body's local microorganism's biome) (Pechal et al., 2014). These interactions provide information about the metabolic line that microorganisms take depending on their environment.

To determine these interactions and metabolic lines, new generation sequencing is the most promising alternative, with specific determinations. This new sequencing technique is able to determine necrobiomas composed of the most diverse organisms such as bacteria, fungi, protists, invertebrates and even vertebrates (Finley et al., 2015).

Pechal et al. (2014) documented necrobioma in decomposing pigs, categorically concluding two observations: 1) The bacterial community of the decomposing body changes during the most diverse stages of decomposition; and 2) The sequencing of these changes during the evolutionary stages of the decomposition can be used to determine IPM $_{\text {MIN }}$. Besides, there is a symptom for current criminal investigations, the so-called "microbial fingerprint". According to recent findings, the individual microbiome does not change during adulthood, thereby developing a unique impression in each individual (Lvet al., 2014). Expectations about these recent discoveries point to assumptions about interactions between individuals from the microbiotic impression, that is, this demonstration could tell which people were involved in the body in the last days.

Finley et al. (2015) exemplified how the use of biome information could be used in criminal investigations. The focus of the scientists was the determination of IPM in relation to the biome in a body's local in an open cornfield. The action is bio-equipment is an important process to verify the Figure 4: 1) Collection of the biome sample in the place and in the body's local; 2) Analysis of the metagenomic sequences using the New Generation Sequencing; 3) Taxonomic Classification based on the sequences found; 4) Determination of IPM.

Another influence of microorganisms permeates at highly promising levels in forensic investigations, including the odor profile of body decomposition. This new technique was investigated by Iqbal et al. (2017) with the most varied demonstrative studies.

The manifestation of the forensic knowledge has been highlighted with gradual advance of verified scientific knowledge. It's observed that such tools have undergone analysis by Entomological Societies and forensic investigators to formalize usage patterns in criminal investigations. The path for such techniques to be enforced for judicial process requires constant protocolization and technical analysis.

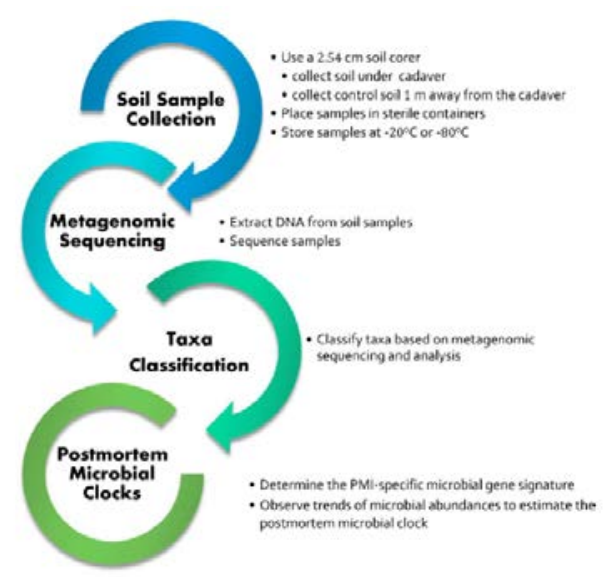

Figure 4. The collection is done in the field and done the metagenomic sequencing, after the classification of the rate by the analysis of sequences is determined the Minimum postmortem interval of the signature and microbial life time. Fonte: Finley et al. (2015). 

analysis

Forensic genetics in criminal

The three key fundamental characteristics for the foundation of an individual's phenotypic construction are: skin color, eye color and hair color. These traits are the main targets for improvement and functional understanding of the triad: genotypephenotype-environment.

Skin color. The environmental factors can directly influence the phenotypic expression of an individual. The evidence for this interference is, e.g. in Africans who, exposed to low rates of ultraviolet radiation, become pale, while Europeans, when exposed to high rates of ultraviolet radiation, and become brown. In addition to this environmental characterization, the genetic properties for determining the color of an individual are due to the activity of melanocytes that vary in different allelic frequencies within a given population.

Maroñas et al. (2014) analyzed SNP disparities among African, European and Afro-European populations, observing relative differences in allele frequency in these populations by spectrometry. These researchers found a very intrinsic relationship between SNPs specific to black, brown and white skin colors from the research donors. In the population with black skin, for example, the following polymorphisms were identified for these colors: rs16891987, rs1426654, rs10777129, rs6058017, rs1408799 and rs1448484. Figure 5 shows the distribution of the polymorphic groups found. In addition to the detection of specific polymorphisms, they found that among the 29 SNPs analyzed in the populations, 10 of these were found in all cases. Finally, the researchers concluded that the functions related to these common SNPs were in the intensity of the skin color of the individuals, being these responsible for the gradations of the colors as can be perceived in Figure 6.

The area of criminal phenotyping analysis, inference about the appearance of individuals can be used as one of the most efficient forms of direct resolution of crimes. Not only in the criminal investigation, but also in the search for missing persons, looking for possible phenotypic changes of age can be used (Maroñas et al., 2014).

Eyes color. The first studies involving the genotypic correlations with the phenotypic characteristics of the eye color were initiated in the year 2007 by the team of Frudakis (2007), detecting 33 SNPs of the OCA2 gene. Subsequently, Sulem and colleagues (2018) inferred in the first studies when GWAS (a database with the main information regarding the multiple allele genes) for pigmentation traits, and identified 9 SNPs in 6 different genomic regions (SLC24A4, KITLG, 6p.25.3 TYR, OCA2-HERC2 and MC1R) associating them with the different ocular pigmentations for the European population (Kayser, 2015).

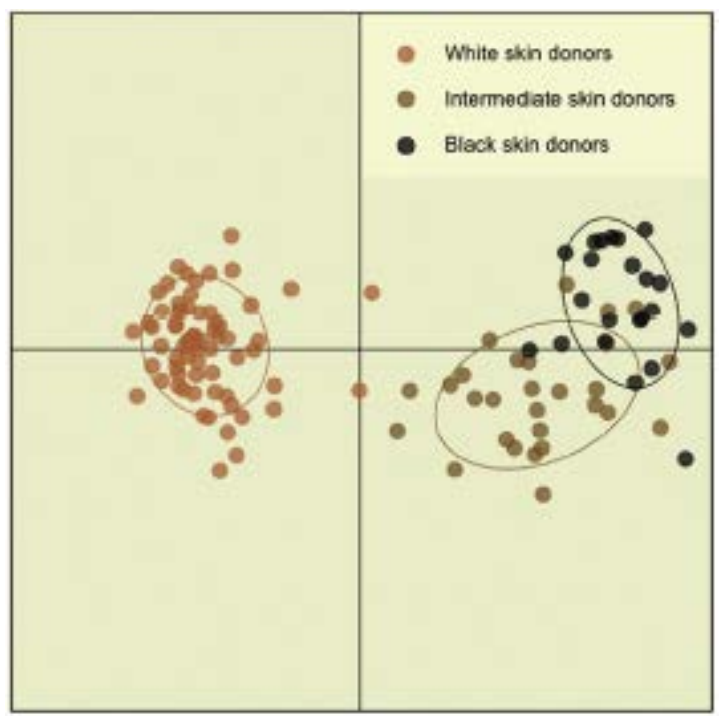

Figure 5. Presentation of the distribution of Single Nucleotide Polymorphisms in different skin colors. Fonte: Maroñas et al. (2014). 
An interesting finding with regard to eye pigmentation is that the variation in the eye color gradient is restricted to European populations, especially the bluish, brown color categories and their intermediates, such as green eyes, for example. However, in the other populations, individuals tend to present a higher percentage of brown eyes, and this line corroborates with the evolutionary point of view in which it points out that the first modern men emerged from the African continent. Eye coloration then emerged as a mutation process occurring and is established in the history of the European population (Walsh et al., 2012). For this reason, studies objectivizing the establishing of an interrelated triad establish the European descendants as a reference population, analyzing the allelic frequencies in this population.

In the year of 2017, Chaitanya et a. (2017) used the HirisPlex genotyping technique - software where information was placed on the 24 markers known today - for phenotypic establishment on eye color for the DNA of over 1000 soldiers killed during World War II. Surprisingly, there was a positive result regarding the analysis of these markers and the data confirmed the phenotype that the photographic records themselves and familiar reports of these same soldiers.

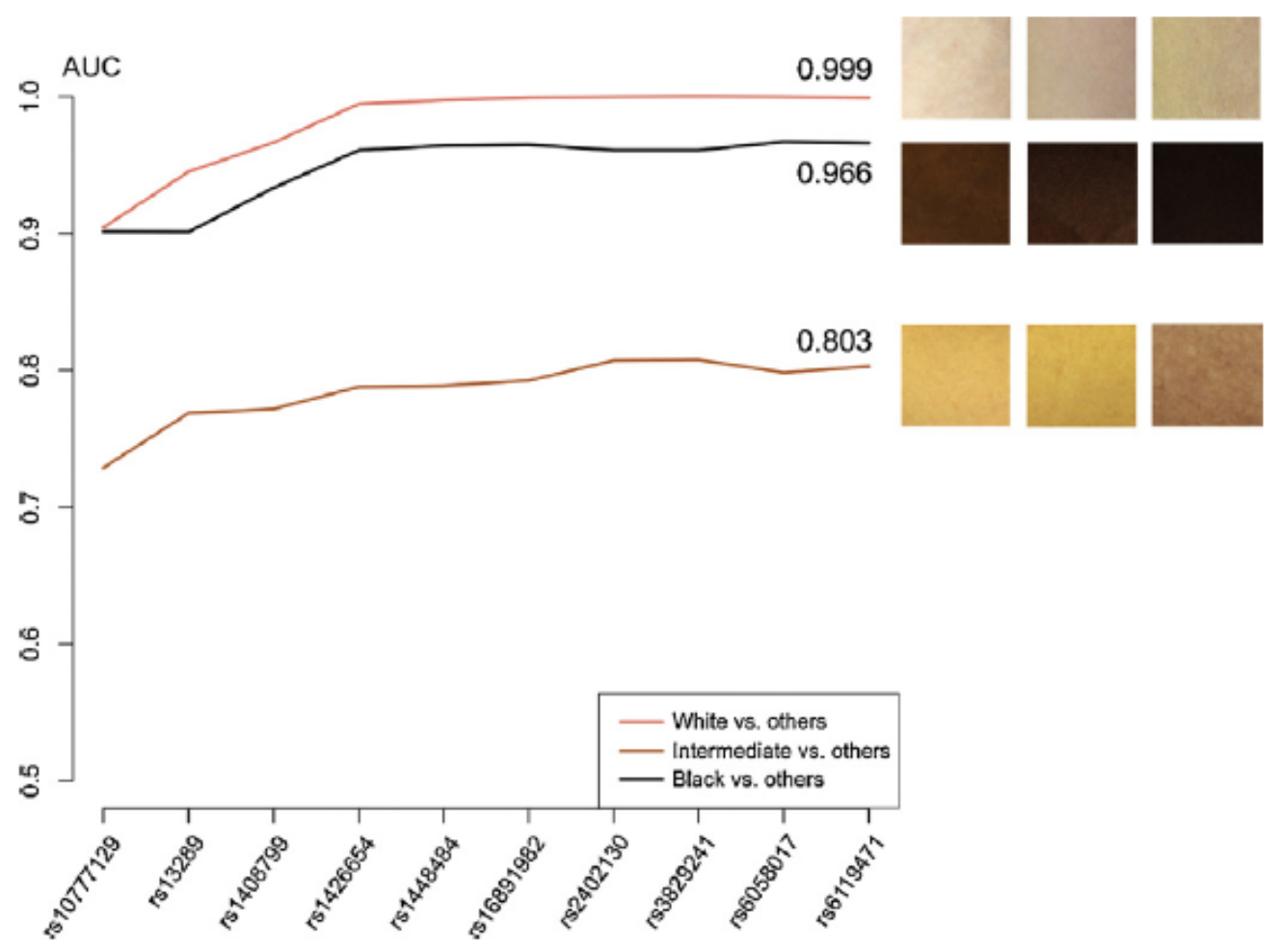

Figure 6. Gradual table of phenotypic variation in the color of individuals. In the X axis are SNPs common to all skin colors. In the $\mathrm{Y}$ axis are the frequencies relative to each SNP. Fonte: Maroñas et al. (2014).

In the now days, a profile was drawn when the distributions of the relative frequencies of the colorations incident in European regions as shown in 
Figure 7. When we take into account this phenotypic aspect of eye color, currently this establishment has been quite widespread and concrete, although the relationship between phenotype and environment is more complex. However, research has advanced and, surprisingly, eye coloring was an indicator directly related to another phenotypic characteristic: hair color (Walsh et al., 2012).

In the phenotyping analyzing, it's observed that the phenotypic determination of an individual is accurate. The relation between gene expression and phenotype occurs from an interaction between the populations characteristics of the individual in relation to the phenotypic characteristics intrinsic to the ancestral population of the same. The environmental characteristics of the individual's own dwelling local that may affect in e.g. the skin color phenotype. Studies have shown that with each new step taken towards phenotypic prediction, more has been understood how environmental, ancestral and genotypic factors can act on the phenotypic formation of an individual (Walsh et al., 2012).

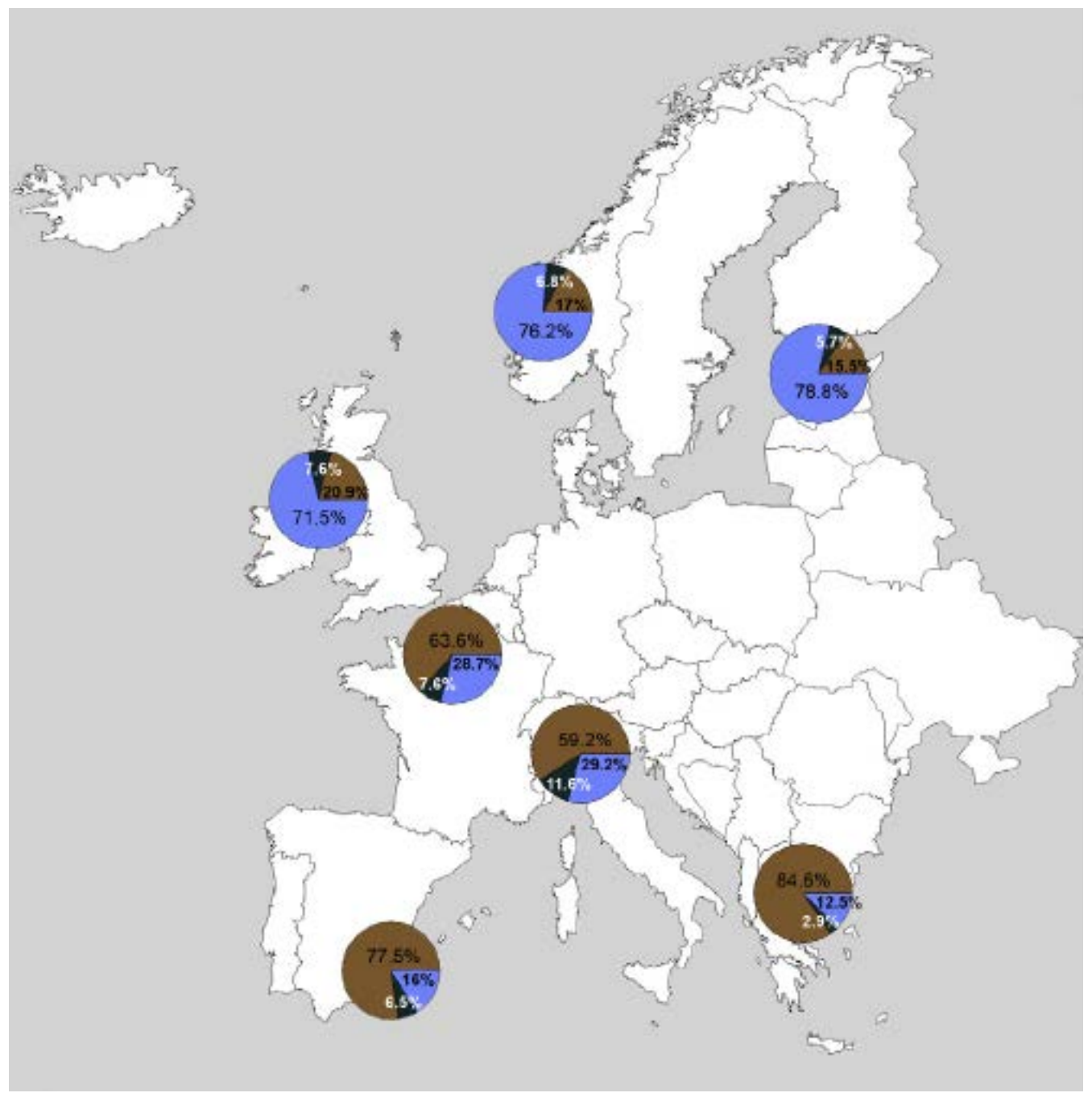

Figure 7. Frequencies regarding the pattern of color distribution of the eyes by Europe. Fonte: Kayser (2015). 
Hair Color. The first test for the definition of SNP regarding hair coloration was performed in 2001 through analyzes of the MC1R gene. The test demonstrated about 21 variations and polymorphisms (Kayser, 2015).

Branicki et al. (2013) performed the first genetic test that had its results from the polymorphisms found in the DNA sample. The so-called HIrisPlex System (Figure 8) includes not only the 24 most common markers for hair color, but also included markers associated with eye coloring.

Only in 2014 was the validation study of the phenotypic method by the
HIrisPlex System based on the compatibility of SWGDAM, the online database for genetic markers of phenotypic characteristics. This regulation for forensic use was mainly based on including in analyzes the characteristics of the place where the individual lived. Even though they do not regulate their ancestry, these data point to the main phenotypic characteristics of some base countries, such as individuals with East Asian, African, Oceania and Native American descent are expected descendants with black hair (Kayser, 2015).

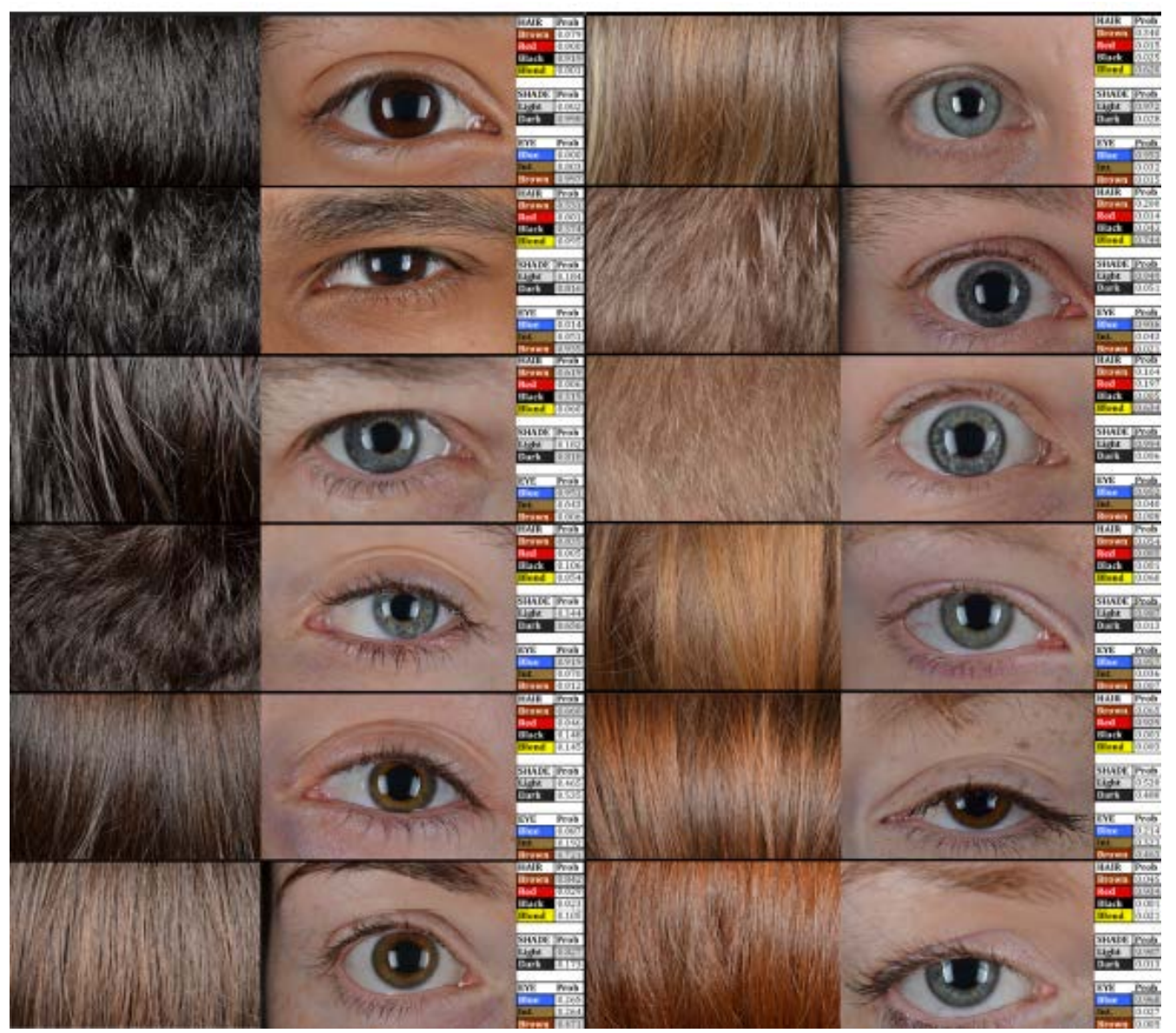

Figure 8. Examples of the HIrisPlex Sistem platform. Fonte: Kayser (2015).

Epigenetic evidence. One of the major difficulties that can occur in criminal investigations is in the identification between twins, especially 
the monozygotic, in which they share the same genome. This sharing of almost identical genetic characteristics makes it difficult, e.g. to identify the true culprit in a criminal investigation, taking into account the identity of the genetic material. According to Vidaki et al. (2017a), a differentiation was possible due to the methylation patterns between both phenotypes that can be observed at the genome level.

Evidence from a pioneering study with blood samples collected from 10 pairs of female twins aged 52 to 56 years showed small variations in DNA methylation that can be attributed to external factors such as environmental exposures and diseases. The identification of tDMSs per pair of MZ twins by the methylation levels of all CpG islands (cytosine and guanine repeat regions) were tested and evaluated using the real-time polymerase chain reaction (qPCR) technique and were successful (67.85\%), while 9 tDMSs $(32.15 \%)$ gave lower methylation differences $(<0.1)$. The interference DNA also showed evidence that one of the twins presented a high methylation profile, while another demonstrated intermediate, unexpected methylation (Vidaki et al., 2017a).

For a forensic applicability, the study still requires the refinement of techniques for obtaining new data for differentiation by the ideal number of epigenetic markers in the identification between MZ twins (Vidaki et al., 2017a).

The evidence among epigenetic marks for the influence of the medium on mammals is not well defined. However, today, it's known that from the patterns of hypo- or hypermethylation in a DNA, one can define the relative age of individuals. Among the targets of investigations regarding the relationship between an individual's age and the environment are the genes H19 and IGF2. Pioneering studies using these genes came from the observation that, over the years, with the advanced number of cell divisions, cells lost part of their ability to methylate some regions of DNA, and among these are the abovementioned (Kader and Ghai, 2015).

Analyzing the degree of methylation in people with relative age of 45 and 75 years, it was observed that these patterns changed and consequently there was a decrease in the methylation sites in the genetic material, concluding that the body itself could not to maintain an efficient response to the environment over the years (Lee et al., 2015).

The different degrees of methylation of an organism vary from the tissues being investigated. As can be seen in Figure 9, the variations and degrees of methylation corresponding to the individual's age behave in different ways in the different markers used.

A way to stand the picture of discoveries, Vidaki et al. (2017b) instill a graph that brings in its axes the comparative paradigms between the age stipulated by degrees of methylation and the real age of the individuals analyzed (Figure 10).

As can be observed, the margin of error applied in the relative analysis of the individuals' age presented minimal differences; however, new studies need to be performed for a more accurate finding as to the prediction of the relative age of the individuals. Even with the margin of error presented, the potential of using this technique applied to forensic analyzes, not only in criminal investigations, but also in the relative applicability of genetics in the understanding of archaeological profiles, is not taken away.

According to Kader and Ghai (2015), the application of the epigenetic analysis can reveal a great applicability in the forensic investigations, especially with regard to the lifestyles of the individuals being able to infer about the characteristics and habits that surrounded or surround the life of this one. For this, the epigenetics had a third great application that was in the inference of these habits of life. 


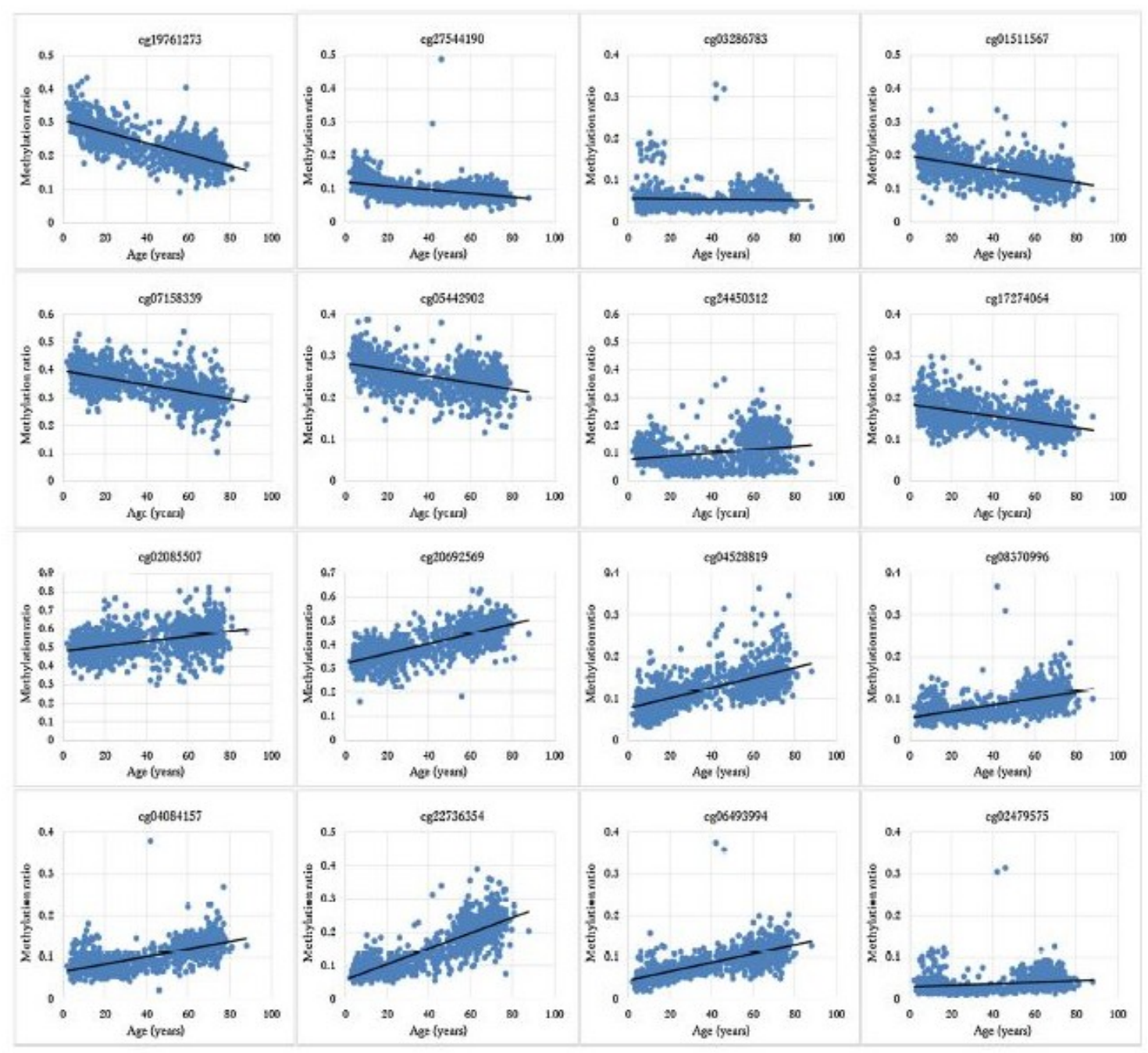

Figure 9. Markers used in the analysis of the different degrees of methylation in the tissues of the body. Fonte: Vidaki et al. (2017b).
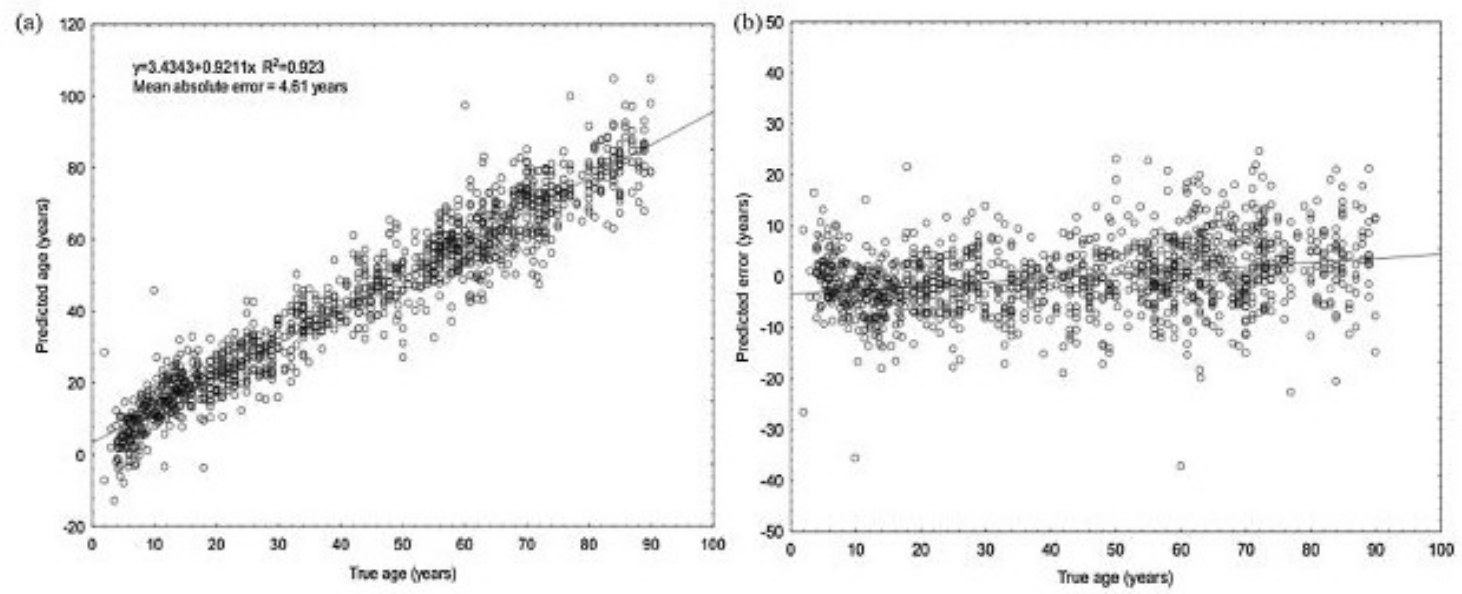

Figure 10. Method of predicting the age of individuals through the degree of methylation. (a) Chronological age of individuals. (b) Errors predicted in the prediction of the relative age of the individuals, with a margin of 5 years. Fonte: Vidaki et al., 2017b). 
To inform the other possible methylation targets and hence susceptibility to epigenetic analysis, it's necessary mention of the nutritional aspects, especially acquired by the mother in gestation. The diet during gestation acts as an indicator for the organism of the fetus as to the conditions it will face when it's born. It's observed that, e.g. from the eating habits and life habits of the mother, the use of drugs like alcohol and tobacco, generates an epigenetic mark in the organism of the fetus, leading to the emergence, as an adult, of diseases associated with cardiovascular system, endocrine system such as susceptibility to diabetes. The use of epigenetics in these cases emerges as a tool to identify the genetic profile of an individual from their life habits, inferring about the methylation profile at DNA level (Kader and Ghai, 2015).

\section{Conclusion}

The development of new methods of forensic investigation either by the amplification of techniques of characterization of species in Forensic Entomology with analysis in microscopy and molecular biology; whether in the use of information from the necrobiota or even molecular analyzes corresponding to the epigenetics and phenotyping of the investigated, today the hypothesis has been raised the applicability of the new discoveries not only in an investigation scenario in the criminal scope, but also in an archeological and forensic analysis the history of human populations.

The nature sciences have prominently gained their forensic attention, serving as a very important foundation in case settlement. Further study of technological advances is needed to ascertain evidence, as well as judicial regulation for the applicability of these technologies. Mutatis mutandis, the forensic scenario with its biological contribution will reach a more prominent level in the judicial analysis and solution of criminal cases with the knowledge regarding its scientific nature.

Epigenetics is a recent tool, discovered in the mid-2000s and needs to be further explored. It's not understood in its entirety how the medium can infer in DNA without modifying its nitrogen bases, and so it is hoped that in the future next, the elucidation of this evidence can be clarified.

Mentioning that ethical aspects still need to be discussed in this context, especially regarding the use of genetic material in criminal investigations, verifying how a better correlation could be made between the law and the use of genetic data of the individuals studied.

\section{Conflicts of interest}

Authors declare that they have no conflict of interests.

\section{References}

Alves, A. C. F.; Santos, W. E.; Farias, R. C. A. P.; Creão-Duarte, A. J. Blowfliers (Diptera, Calliphoridae) associated with pig carcasses in a Caatinga area, Northeastern Brazil. Neotropical Entomology, v. 43, n. 2, p. 122126, 2014. https://doi.org/10.1007/s13744013-0195-4

Carriço, C.; Mendonça, P. M.; Cortinhas, L. B.; Mallet, J. R.; Queiroz, M. M. Ultrastructural studies of some character of Diptera (Muscidae) of forensically importance. Acta Tropical, v. 142, p.96-102, 2014. https://doi.org/10.1016/j.actatropica.2014.1 1.005

Chaitanya, L.; Pajnič, I. Z.; Walsh, S.; Balažic, J.; Zupanc, T.; Kayser, M. Bringing colour back after 70 years: Predicting eye and hair colour from skeletal remains of World War II victims using the HIrisPlex System. Forensic Science International: Genetics, v. 26, p. 48-57, 2017. https://doi.org/10.1016/ j.fsigen.2016.10.004

Fagertun, J. Wolffhechel, K.; Pers, T.H.; Nielsen, H. B.; Gudbjartsson, D.; Stefansson, H.; Stefansson, K.; Paulsen, R. R.; Jarmer, H. Predicting facial characteristics from complex polygenic variations. Forensic Science International: Genetics, v. 19, p. 
263-268, 2015. https://doi.org/10.1016/ j.fsigen.2015.08.004

Finley, S. J.; Benbow, M. E.; Javan, G. T. Potential applications of soil microbial ecology and next-generation sequencing in criminal investigations. Applied Soil Ecology, v. 88, no. 1, p. 69-78, 2015. https://doi.org/10.1016/j.apsoil.2015.01.00 1

Hebert, P. D. N.; Gregory, T. R. The promise of DNA barcoding for taxonomy. Systematic Biology, v. 54, n. 5, p. 852-859, 2005.

Iqbal, M. A.; Katie, D.; Maiken, N. U.; Forbes, S. L. Forensic decomposition odour profiling: A review of experimental designs and analytical techniques. TrAC Trends in Analytical Chemistry, v. 91, p.112-124, 2017. https://doi.org/10.1016/j.trac.2017. 04.009

Kader, F.; Ghai, M. DNA methylation and application in forensic sciences. Forensic Science International, v. 249, p. 255-265, 2015. https://doi.org/10.1016/j.forsciint. 2015.01.037

Kayser, M. Forensic DNA Phenotyping: Predicting human appearance from crime scene material for investigative purposes. Forensic Science International: Genetics, v. 18 , p. 33-48, 2015 . https://doi.org/ 10.1016/j.fsigen.2015.02.003

Lee, H. Y.; Jung S. E.; Oh, Y. N.; Choi, A.; Yang, W. I.; Shin K. J. Epigenetic age signatures in the forensically relevant body fluid of semen: a preliminary study. Forensic Science International: Genetics, v. 19, p. 28-34, 2015. https://doi.org/10.1016/j.fsigen.2015. 05.014

Mądra, A.; Frątczak, K.; Grzywacz, A.; Matuszewski, S. Long-term study of pig carrion entomofauna. Forensic Science International, v. 1, no. 252, p. 1-10, 2015.

Maroñas, O.; Phillips, C.; Söchtig, J.; GomezTato, A.; Cruz, R.; Alvarez-Dios, J.; Casares de Cal, M.; Ruiz, Y.; Fondevila, M..; Carracedo, A.; Lareu, M. V. Development of a forensic skin colour predictive test. Forensic Science International: Genetics, v. 13, p. 34-44, 2014. https://doi.org/10.1016/j.fsigen.2014. 06.017

Pechal, J. L.; Crippen, T. L.; Benbow, M. E.; Tarone, A. M.; Dowd, S.; Tomberlin, J. K. The potential use of bacterial community succession in forensics as describedby high throughput metagenomic sequencing. International Journal of Legal Medicine, v. $128, \quad$ no. $1, \quad$ p. 193-205, 2014. https://doi.org/10.1007/s00414-013-0872-1

Pentinsaari, M.; Mutanen, M.; Kaila L. Cryptic diversity and signs of mitochondrial introgression in the Agrilusviridis species complex (Coleoptera: Buprestidae). European Journal of Entomology, v. 1, no. 111, p. 475-486, 2014. https://doi.org/ 10.14411/eje.2014.072

Samerjai, C.; Sanit, S.; Sukontason, K.; Morakote, N.; Wannasan, A.; Pereira, R. M.; Sukontason, K. L. Morphology of immature stages of flesh flies, Boettcherisca nathani and Lioproctia pattoni (Diptera: Sarcophagidae). Acta Tropical, v. 163, p. 109-120, 2016. https://doi.org/10.1016/j.actatropica.2016.0 8.008

Sharma, R.; Garg, R. K.; Gaur, Jr. Various methods for the estimation of the postmortem interval from Calliphoridae: A review. Egyptian Journal of Forensic Sciences, v. 5, no. 1, p. 1-12, 2013. https://doi.org/1 0.1016/j.ejfs.2013.04.002

Szpila, K.; Mądra, A.; Jarmusz, M.; Mateuszewski, S. Flesh flies (Diptera: Sarcophagidae) colonising large carcasses in Central Europe. Parasitology Research, v. 114, no. 114, p. 2341-2348, 2015. https://doi.org/10.1007/s00436-015-44311

Tsang, L. M.; Chu, K. H.; Nozawa, Y.; Chan, B. K. K. Morphological and host specificity evolution in coral symbiont barnacles (Balanomorpha: Pyrgomatidae) inferred from a multi-locus phylogeny. Molecular Phylogenetic Evolution, v. 1, no. 77, p.11-22, 2014. https://doi.org/10.1016/ j.ympev.2014. 03.002

Tuccia, F.; Giordani, G.; Vanin, S. A general review of the most common COI primers for Calliphoridae identification in forensic entomology. Forensic Science International: Genetics, v. 24, no. 1, p. 9-11, 2016. https://doi.org/10.1016/j.fsigen.2016. 07.003

Tuccia, F.; Giordani, G.; Vanin, S. Epigenetic discrimination of identical twins from blood under the forensic scenario. Forensic Science International: Genetics, v. 31, p. 67-80, 2017a. https://doi.org/10.1016/ j.fsigen.2017.07.014

Vidaki, A.; Ballard, D.; Aliferi, A.; Miller, T. H.; Barron, L. P.; Court, D. S. DNA methylationbased forensic age prediction using artificial neural networks and next generation 
sequencing. Forensic Science

International: Genetics, v. 28, p. 225-236, 2017b. https://doi.org/10.1016/j.fsigen. 2017.02.009

Virmond, M. B.; Robert, A. W.; Brito, P. B.; Massuda, T. Y. C. Fenotipagem forense pelo DNA através de SNPs. Revista Brasileira de Criminalística, v. 5, no. 2, p. 37-47, 2016. https://doi.org/10.15260/rbc.v5i2.128

Walsh, S.; Wollstein, A.; Liu, F.; Chakravarthy, U.; Rahu, M.; Seland, J. H.; Soubrane, G.; Tomazzoli, L.; Topouzis, F.; Vingerling, J. R.; Vioque, J.; Fletcher, A. E.; Ballantyne, K. N.; Kayser, M. DNA-based eye colour prediction across Europe with the IrisPlex system. Forensic Science International: Genetics, v. 6, no. 3, p. 330-340, 2012. https://doi.org/ 10.1016/j.fsigen.2011.07.009
Zajac, B. K.; Martin-Vega, D.; Feddern, N.; Fremdt, H.; Castro, C. P.; Szpila, K.; Reckel, F.; Schutt, S.; Verhoff, M. A.; Amendt, J.; Zehner, R. Molecular identification and phylogenetic analysis of the forensically important Family Piophilidae (Diptera) from different European locations. Forensic Science International, v. 259, no. 1, p. 77-84, 2016. https://doi.org/10.1016/j.forsciint.2015.12. 024

Zanetti, N. I.; Visciarelli, E. C.; Centeno, N. D. Marks caused by the scavenging activity of Necrobia rufipes (Coleoptera: Cleridae) under laboratory conditions. Journal of Forensic and Legal Medicine, v. 33, p. 116-120, 2015. https://doi.org/10.1016/j.jflm.2015.04.020 